\title{
High Pollution Loadings Influence the Reliability of Himawari-8 Cloud-Mask in Comparison with Space-Based Lidar and Surface Observations
}

\author{
Wei Wang $\mathbb{D}^{1},{ }^{1}$ Pengfei Tong, ${ }^{1}$ Huihui Feng ${ }^{D},{ }^{1}$ and Weiwei $X u^{2}$ \\ ${ }^{1}$ School of Geosciences and Info-Physics, Central South University, Hunan, China \\ ${ }^{2}$ School of Remote Sensing and Information Engineering, Wuhan University, Hubei, China \\ Correspondence should be addressed to Huihui Feng; hhfeng@csu.edu.cn
}

Received 6 July 2021; Revised 26 November 2021; Accepted 2 February 2022; Published 27 February 2022

Academic Editor: Pedro Jiménez-Guerrero

Copyright (c) 2022 Wei Wang et al. This is an open access article distributed under the Creative Commons Attribution License, which permits unrestricted use, distribution, and reproduction in any medium, provided the original work is properly cited.

Cloud identification methods of passive sensors are usually on the basis of different thresholds at different wavelengths. However, the high pollution levels may contribute to the misidentification of cloud mask of Advanced Himawari Imager (AHI) carried on Himawari-8. This study comprehensively analyses and demonstrates this possibility by comparing the AHI cloud-masks and space-based lidar observations based on surface observations of air-polluted loadings from January 1, 2016, to December 31, 2019. Therefore, this study comprehensively explores this impact by comparing the AHI cloud-masks and space-based lidar observations by using surface observations of air-polluted loadings from January 1, 2016, to December 31, 2019. Case studies that compare the two sensors indicate that the performance of AHI cloud detection is degenerative during aerosol events. Long-term statistical analysis demonstrates that the average hit ratio of clear (cloud) between the two sensors during the period is $79 \%$ (63\%) and the consistency (hit rate) of cloud-mask between AHI and CALIOP decreases with increasing pollution levels. On the contrary, the low uncertainty ratios with $15 \%$ of cloud and $3 \%$ of clear exist in low $\mathrm{PM}_{2.5}$ levels (lower than $40 \mu \mathrm{g} / \mathrm{m}^{3}$ ), while the high uncertainty ratios with $47 \%$ of cloud and $15 \%$ of clear exist in high $\mathrm{PM}_{2.5}$ levels (higher than $130 \mu \mathrm{g} / \mathrm{m}^{3}$ ). Therefore, results demonstrate that the reliability of AHI cloud-mask is weakened by high air-polluted levels. Further improvement of AHI cloudmask algorithm is desired because AHI products with high temporal resolution are vital in several related fields, such as climate change, aerosol-cloud interaction, and air-polluted mapping.

\section{Introduction}

Clouds not only have a significant influence on the radiation balance of the Earth by reflecting the short-wave radiation from the sun, absorbing and emitting infrared radiation, but also mainly affect regional precipitation and other environmental conditions $[1,2]$. Therefore, developing advanced tools to monitor spatiotemporal evolution of cloud accurately and effectively around the Earth is important [3-5].

Satellite-based sensors break through the spatial limitations of site-based observation; they can derive the cloud parameters on a large spatial scale, such as MODIS (Moderate Resolution Imaging Spectroradiometer) $[2,6]$. In recent years, owing to the development of geostationary satellites, cloud layers are monitored with high temporal resolution for a large-scale region. Advanced Himawari Image (AHI), a new generation of high-performance sensor carried by meteorological satellite Himawari-8 launched by Japan in October 2014 [7], can detect cloud parameters with 10-minute resolutions in East Asia [8,9]. Himawari-8 cloud product is important to the research on weather forecast and environmental monitoring $[10,11]$; it also provides a key parameter for aerosol retrievals $[1,12,13]$. However, some studies point out that the performances of AHI aerosol retrievals from cloud edge are lower than those from clear pixels. This result implies that the AHI cloud-mask product should be evaluated prior to application in scientific research and be improved as quickly as possible.

Investigating possible factors that mislead AHI cloud identification is crucial to improve current algorithms for 
recognizing cloud pixel on a satellite-derived image $[14,15]$. For example, a recent research has pointed out that high aerosol loading, such as haze, reduces the ability of MODIS cloud detection [2]. Therefore, the AHI cloud-mask product algorithm developed by the Japan Meteorological Satellite Center may inaccurately identify aerosols and clouds under extreme conditions. To clarify the issue, this study aims to explore the impact of aerosol on the reliability of its Himawari-8/AHI cloud-mask by an active sensor with an excellent cloud identification ability, namely, Cloud-Aerosol Lidar with Orthogonal Polarization (CALIOP) carried by Cloud-Aerosol Lidar and Infrared Pathfinder Satellite Observation (CALIPSO) $[16,17]$. As active sensor, lidar can not only retrieve aerosol layers $[18,19]$, wind fields $[20]$, and leaf biochemical properties [21] but also locate cloud height and retrieve cloud optical properties. The space-based lidar has been applied to evaluate the reliability of the cloud detection algorithm of different sensors $[2,14]$.

In summary, this study attempts to investigate whether the aerosol misguides AHI cloud recognition based on CALIOP cloud observations. The materials and methods are described in Section 2. Section 3 presents the case and longterm analysis. Some conclusions are given in Section 4.

\section{Materials and Methodology}

The present study uses datasets, mainly including hourly AHI cloud-mask, CALIPSO vertical feature mask (VFM), and site-based $\mathrm{PM}_{2.5}$ observation from January 1, 2016, to December 31, 2019. Beijing-Tianjin-Hebei region, the most polluted region in East Asia, was selected as the study area due to its high pollution levels [22]. Moreover, abundant surface observations of air-polluted loadings over the study region have been established to monitor air quality. The red line in Figure 1 refers to CALIPSO trajectories in daytime. These trajectories repeat every 16 days.

\subsection{Materials}

2.1.1. Himawari-8 Level 1 Data. The meteorological satellite Himawari-8 was launched and operated by the Japan Meteorological Agency on October 7, 2014, and since July 7, 2015, respectively. The AHI spatiotemporal resolutions are $0.5 \mathrm{~km}$ and $10 \mathrm{~min}$. Himawari-8/AHI sensor has 10 infrared channels, three near-infrared channels, and three visible lights (red, green, and blue) to capture atmospheric information. AHI is widely used in cloud retrievals [13] and aerosol data assimilation [7, 23].

The Japan Meteorological Satellite Center has developed the cloud-mask product algorithm of Himawari- 8 on the basis of the AHI data. The cloud-mask algorithm benefits cloud detection after comparing the clear sky hold data, which are calculated using the numerical weather prediction (NWP) data, with the observed data. If the observed data differ from the clear sky data, then the pixel is determined to be a cloud pixel point. The clear sky threshold value in the cloud-mask algorithm is estimated using a radiation transfer. The threshold is obtained from the NWP atmospheric profile data. However, the threshold data calculated by this method are seldom reliable. Therefore, certain offsets should be added as thresholds [24]. In this algorithm, in addition to the large number of cloud detection tests, aerosol detection tests and other tests are included. AHI sensors may inaccurately identify aerosols and clouds under extreme weather conditions. The cloud detection of Himawari-8/AHI may be misjudged under heavy aerosol conditions.

\subsubsection{CALIPSO Cloud and Aerosol Products. CALIPSO,} which carries CALIOP (a lidar with polarized light for cloud and aerosol detection), was launched in 2006 [25]. CALIPSO has a frequency of $20.16 \mathrm{~Hz}$ at 532 and $1064 \mathrm{~nm}$. CALIPSO has various vertical resolutions for different altitudes, i.e., the resolution is lower at the higher altitudes. In areas covering the ground to the altitude of $8.2 \mathrm{~km}$, the vertical resolution is $30 \mathrm{~m}$, and the horizontal resolution is $33 \mathrm{~m}$. The horizontal and the vertical resolutions are $5 \mathrm{~km}$ and $300 \mathrm{~m}$ at altitudes of $30-40 \mathrm{~km}$, respectively. The VFM3.01 data of CALIPSO provide feature classifications, including vertical profiles, clouds, aerosols, and other features $[25,26]$. The data on color ratio and backscatter intensity can be used to identify clouds and aerosols because the backscatter intensity of clouds is higher than that of aerosols. However, optically thick aerosols may be mistakenly recognized as cloud layers; this problem can be attributed to the color ratio and backscatter intensity of optically thick aerosols that are highly similar to those characteristics of clouds under heavy aerosol [27]. Generally, CALIOP has a significant cloud detection ability and is usually considered to have stronger capabilities than a passive sensor $[28,29]$.

2.1.3. Surface Polluted Levels. Figure 1 displays approximately $1500 \mathrm{PM}_{2.5}$ observed sites in China. These sites have been managed and operated by the China National Environmental Monitoring Center (CNEMC). The observed data are real-time updated and released in the website of CNEMC (http://www.cnemc.cn). Hourly $\mathrm{PM}_{2.5}$ measurements from January 1, 2016, to December 31, 2019, derived from the sharing website were used in this study. This traditionally measured technique near the ground offers reliable $\mathrm{PM}_{2.5}$ observations [30].

\subsection{Methodology}

2.2.1. Matching Criteria. The criteria for matching the AHI, CALIOP, and ground measurements are as follows: (1) the CALIOP and AHI are within a 10-minute time interval and a $5 \mathrm{~km}$ radius space interval and (2) the in situ measurements matched the satellite-based retrievals (AHI-CALIOP matchups) by a matching time window of 1 hour and space window of $5 \mathrm{~km}$.

2.2.2. Hit and Uncertainty Ratios. The AHI cloud-mask product has four confidence levels as follows: "cloudy," "probably cloudy", "probably clear," and "clear." The two flags of "probably cloudy" and "probably clear" can be regarded as the uncertainty for "cloudy" and "clear." If two 


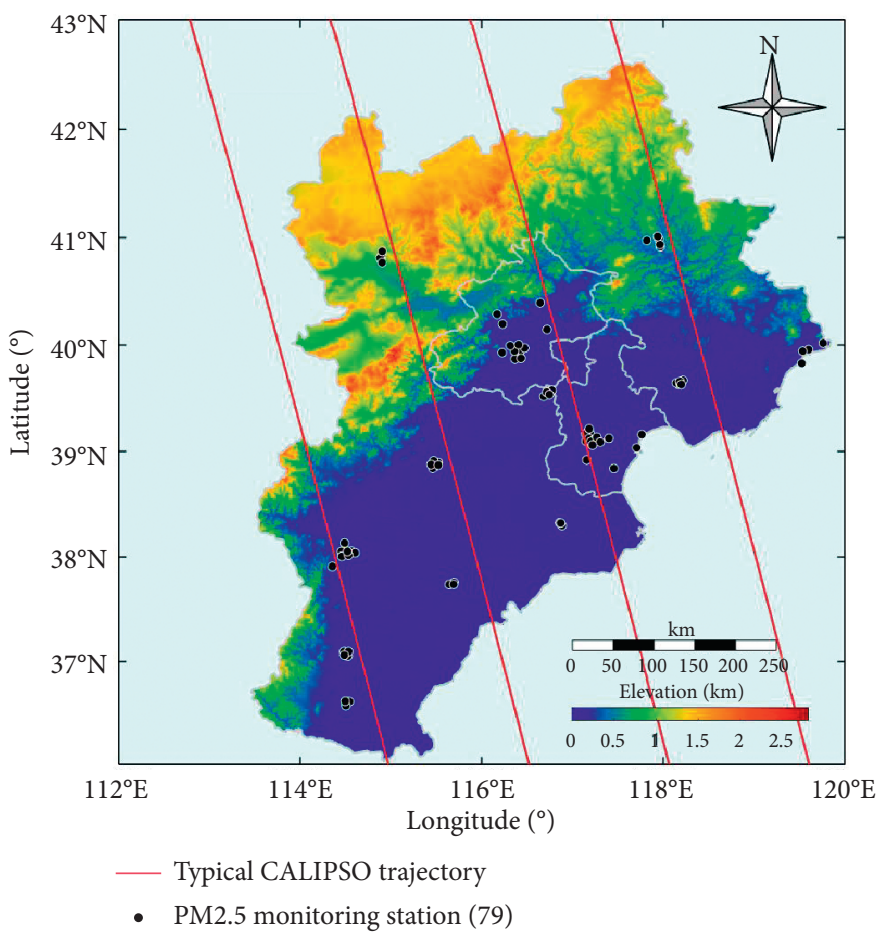

Figure 1: Observed zones of Himawari-8/AHI over Beijing-Tianjin-Hebei and the typical CALIPSO trajectories at daytime. $\mathrm{PM}_{2.5}(\mathrm{black}$ dots) observed sites are managed and operated by the China National Environmental Monitoring Center (CNEMC).

satellite-based sensors (AHI and CALIOP) judge a pixel for the same grid as cloudy or clear at the same time, then the pixel point is considered in agreement; otherwise, it is regarded to be an inconsistent point. In the research of Mao et al. [2], hit ratio $(H R)$ has been designed and defined to quantify the consistency of cloud-mask between AHI and CALIOP at a pixel level, as follows:

$$
\left\{\begin{array}{l}
H R_{\text {cloudy }}=\frac{N_{\text {cloudy }}}{N_{\text {all }}} \times 100 \%, \\
H R_{\text {clear }}=\frac{N_{\text {clear }}}{N_{\text {all }}} \times 100 \%,
\end{array}\right.
$$

where $N_{\text {cloudy }}$ refers to the consistent cloud pixel number, $N_{\text {clear }}$ indicates the consistent clear pixel number, and $N_{\text {all }}$ refers to the total sample numbers of matched pixels derived from AHI and CALIOP in a grid. Then, the uncertainty ratio $(U R)$ for "cloudy" and "clear" can be calculated by

$$
\left\{\begin{array}{l}
U R_{\text {cloudy }}=\frac{N_{\text {cloud }}^{\text {uncertainty }}}{N_{\text {all }}} \times 100 \%, \\
U R_{\text {clear }}=\frac{N_{\text {clear }}^{\text {uncertainty }}}{N_{\text {all }}} \times 100 \%,
\end{array}\right.
$$

where $N_{\text {cloud }}^{\text {uncertainty }}\left(N_{\text {clear }}^{\text {uncertainty }}\right)$ refers to the number of cloud (clear) pixel with a confidence level of "probably cloudy (clear)" and "probably clear" in a grid and $N_{\text {all }}$ refers to the total sample numbers of matched pixels derived from AHI and CALIOP in a grid.

\section{Results and Discussion}

The cloud-mask retrieved by AHI and CALIOP was compared from January 1, 2016, to December 31, 2019. The comparisons were implemented by three typical cases to investigate the performance of the AHI cloud-mask under various pollution levels. Then, a long-term statistical comparison was executed between AHI and CALIOP.

3.1. Case Analysis. Three typical cases under different pollution levels, namely, "slight," "moderate," and "heavy," are used to analyze the impact of polluted loadings on the AHI cloud-mask detection.

3.1.1. Low Pollution Level. A case with low aerosol levels (average AOD is approximately 0.17 ) was selected to compare the cloud-masks retrieved from AHI and CALIOP on May16, 2017. Figure 2(a) shows the AHI cloud-mask (background) and CALIPSO trajectory (red-green solid line) over East Asia at 05:33 UTC. The different colors of the redgreen solid line manifest the cloud-mask consistency between AHI and CALIOP, with red for consistency and green for inconsistency. Figure 2(b) presents the vertical distribution of clouds and aerosols derived from CALIOP VFM (vertical feature mask). Figure 2(c) displays the aerosol types, including sea water, smoke, dust, and other types, retrieved by CALIOP. In addition, Figure 2(d) displays the cloudmask of AHI and CALIOP AOD along the CALIPSO trajectory. Same as Figure 2(a), this figure displays the cloudmask consistency between AHI and CALIOP, with red for consistency and green for inconsistency. 


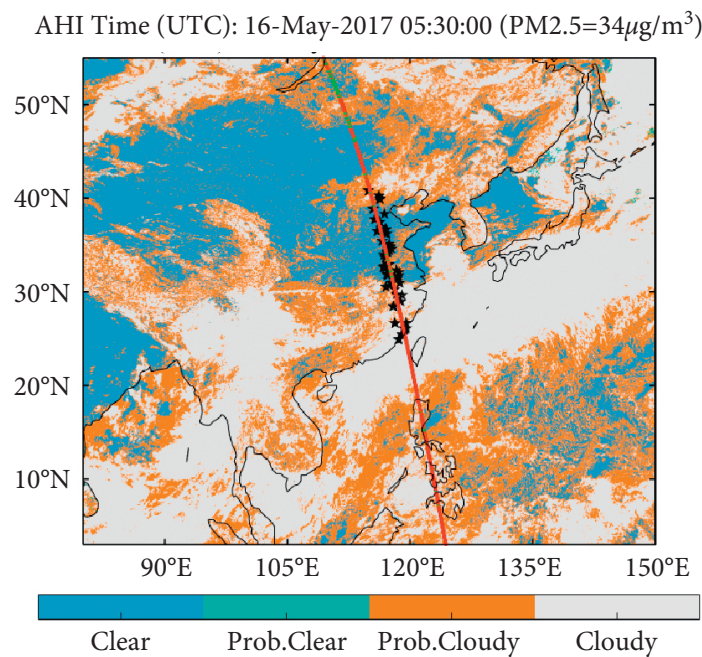

(a)

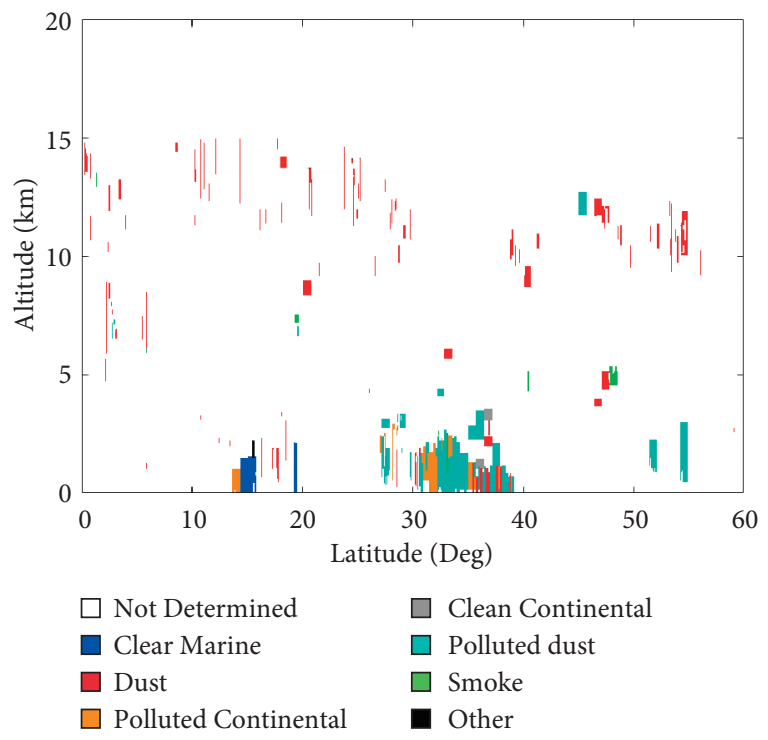

(c)

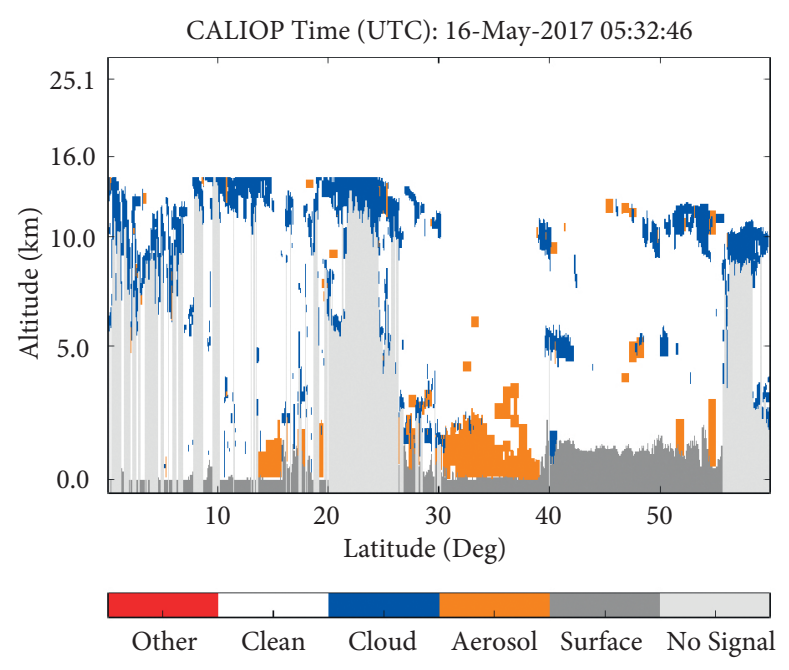

(b)

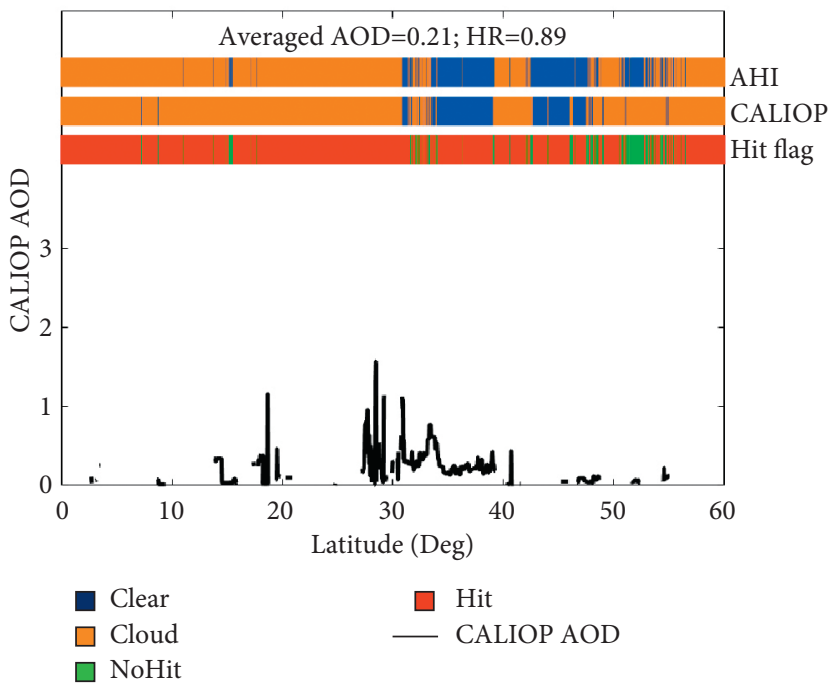

(d)

FIgUre 2: Comparison at 05:30 UTC, 16 May 2017. (a) AHI cloud-mask and the consistency line between AHI and CALIOP, with red for consistency and green for inconsistency; the black pentagrams refer to the in situ PM2.5 measurements. (b) VFM retrieved by CALIOP. (c) Aerosol types detected by CALIOP. (d) Cloud-mask of AHI and CALIOP AOD along the CALIPSO trajectory.

The average PM2.5 loading and CALIOP AOD along the CALIPSO trajectory at 05:30 UTC, 16 May 2017, was $34 \mu \mathrm{g} /$ $\mathrm{m}^{3}$ and 0.21 , respectively, indicating low aerosol loading in this case. The CALIOP signals were fully attenuated by thick cloud layers, and the cloud bases were undetected from $0^{\circ} \mathrm{N}$ to $30^{\circ} \mathrm{N}$. Meanwhile, AHI can detect the thick cloud layers consistently with CALIOP along this same track range. Evidently, the disagreements of cloud-mask determined by AHI and CALIOP are relatively higher at $30^{\circ} \mathrm{N}$ to $35^{\circ} \mathrm{N}$ than in other regions, which are consistent with the high aerosol loadings (AOD $>1$ ) retrieved by CALIOP for this zone. In this region, although CALIOP and AHI detected cloud layers, the identified cloud pixels from CALIOP and AHI are different. The polluted dust (Figure 2(c)) below these broken clouds (Figure 2(b)) negatively influences the AHI cloud detection. Similar reflection characteristics of the aerosol and cloud may result in AHI misinformation of some specific clouds between $32^{\circ} \mathrm{N}$ and $24^{\circ} \mathrm{N}$. In summary, the high hit ratio (0.89) signifies the cloud-mask consistency detected by comparing the two different sensors under clear conditions.

3.1.2. Moderate Pollution Level. Figure 3(a) displays a case with intermediate aerosol levels with average PM2.5 level $\left(65 \mu \mathrm{g} / \mathrm{m}^{3}\right)$ and AOD $(0.46)$ on 28 February 2018. Figure 3(b) shows consecutive low broken clouds from $26^{\circ} \mathrm{N}$ to $34^{\circ} \mathrm{N}$ and consecutive aerosol layers from $34^{\circ} \mathrm{N}$ to $43^{\circ} \mathrm{N}$ (the blue circle in Figure 3(b)). The consecutive aerosol layers consist of dust (high), polluted dust (middle), and smoke (low), as shown in Figure 3(c). CALIOP cloud-mask marked the pixels mixing the aerosol layers and broken cloud layers as cloud, by 


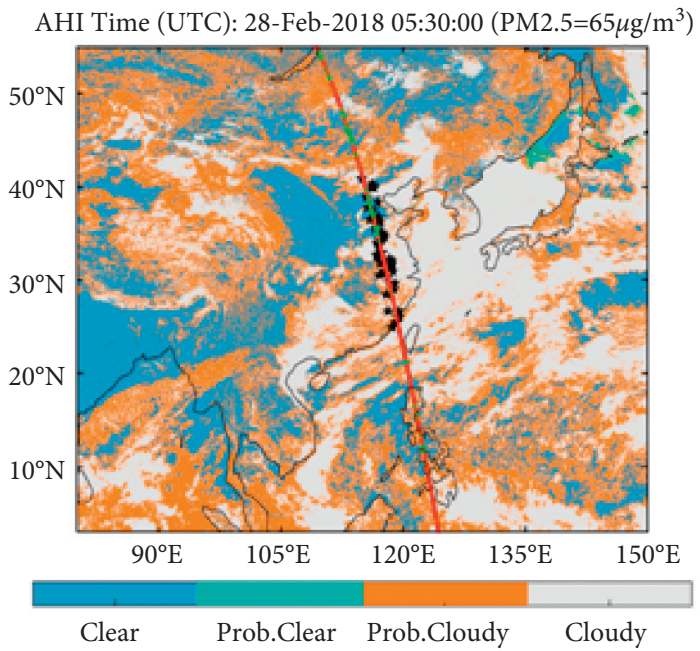

(a)

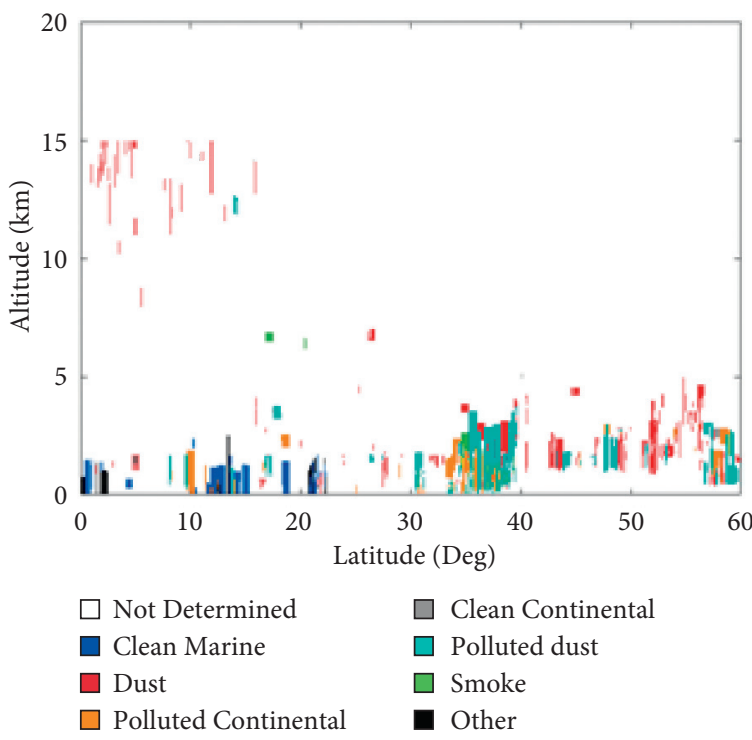

(c)

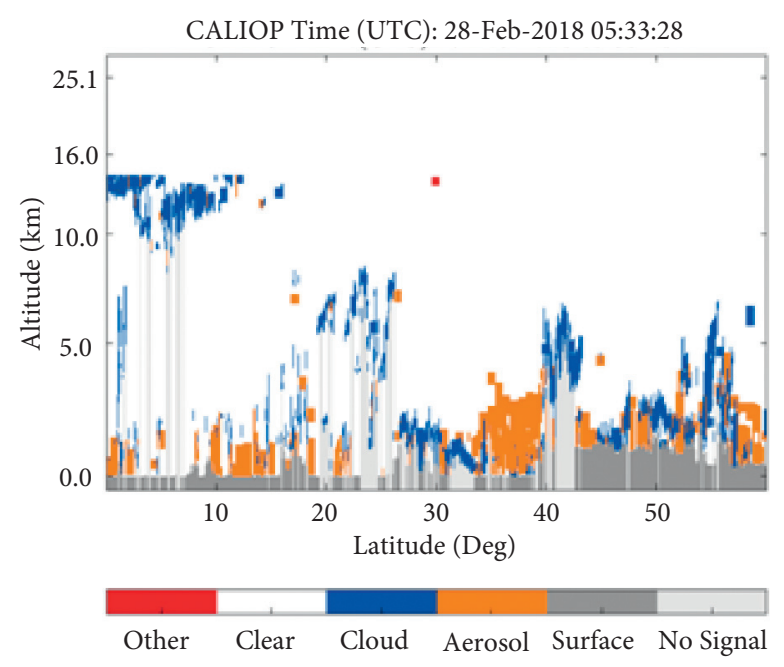

(b)

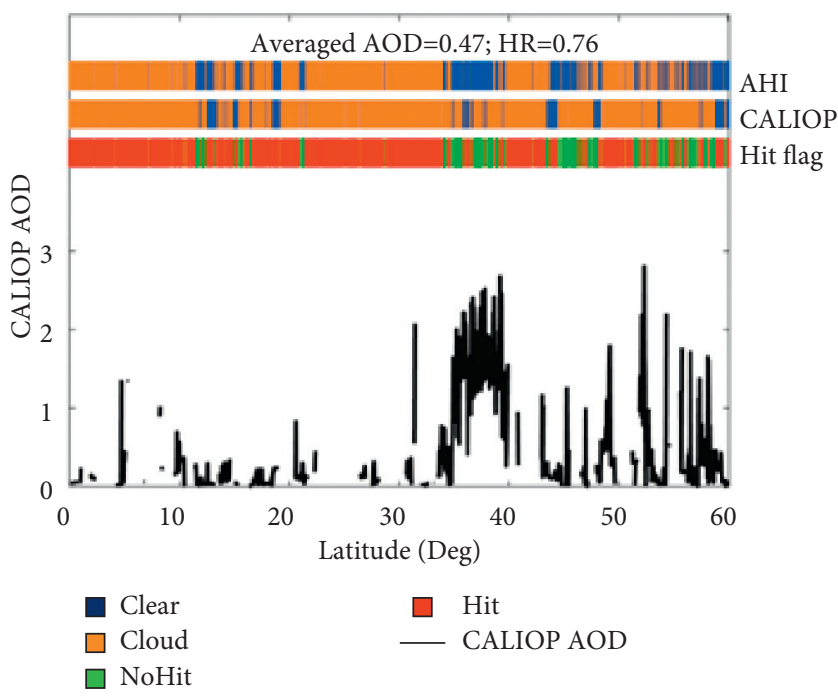

(d)

FIgURe 3: Comparison at 05:30 UTC, 28 February 2018. (a) AHI cloud-mask and the consistency line between AHI and CALIOP, with red for consistency and green for inconsistency; the black pentagrams refer to the in situ PM2.5 measurements. (b) VFM retrieved by CALIOP. (c) Aerosol types detected by CALIOP. (d) Cloud-mask of AHI and CALIOP AOD along the CALIPSO trajectory.

comparing Figure 3(b) (blue circle) and Figure 3(d) (blue rectangle). Nevertheless, most broken clouds detected by CALIOP were missed by AHI, as shown in Figure 3(d). The difference between AHI and CALIOP mostly existed in the region with high pollution loadings from $35^{\circ} \mathrm{N}$ to $40^{\circ} \mathrm{N}$. Therefore, the high pollution loadings may result in the poor performance of AHI on identifying broken clouds to some extent. Comparatively, the region with low polluted loadings ranges from $10^{\circ} \mathrm{N}$ to $240^{\circ} \mathrm{N}$, and the consistency of AHI and CALIOP on identifying low broken cloud was higher than that in the regions from $35^{\circ} \mathrm{N}$ to $40^{\circ} \mathrm{N}$. In summary, the medium hit rate (76\%) between AHI and CALIOP indicates high consistency of the two types of cloud and aerosol detection results under moderate pollution level.
3.1.3. Heavy Pollution Level. The heavy pollution case on 14 December 2016 was selected to further investigate the possible influence of high polluted levels on AHI cloud identification, as shown in Figure 4(a). The average PM2.5 loading and CALIOP AOD along the CALIPSO trajectory were $120 \mu \mathrm{g} / \mathrm{m}^{3}$ and 0.28 , respectively. The low mean AOD may be influenced by the clear region from $0^{\circ} \mathrm{N}$ to $25^{\circ} \mathrm{N}$. The purple ellipse in Figure $4(\mathrm{~b})$ marked a region from $30^{\circ} \mathrm{N}$ to $36^{\circ} \mathrm{N}$, displaying inconsistent pixels of cloud and aerosol from AHI and CALIOP. Correspondingly, high aerosol loadings with AOD $>2.0$ existed in this region (Figure 4(b)). Various types of aerosol types, such as polluted dust, smoke, and polluted continental, contribute to these high pollution levels (Figure 4(c)). Interestingly, the AHI flagged the pixels 


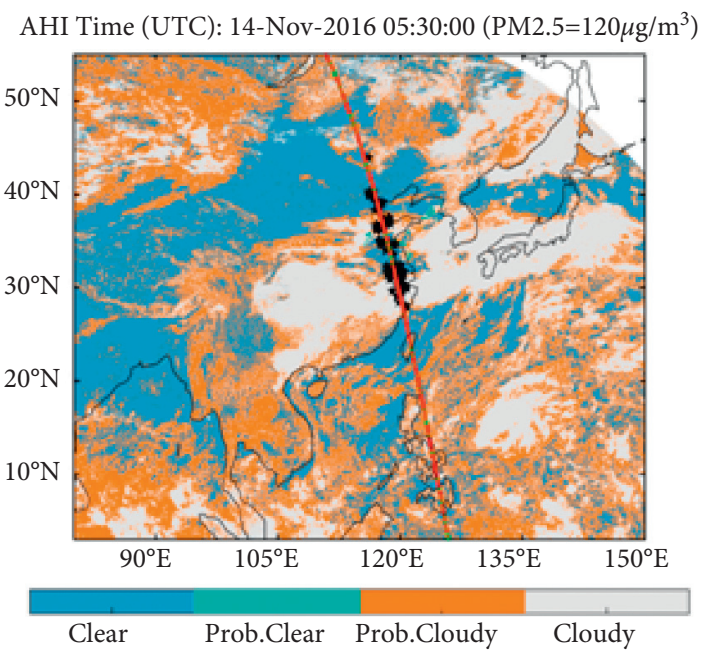

(a)

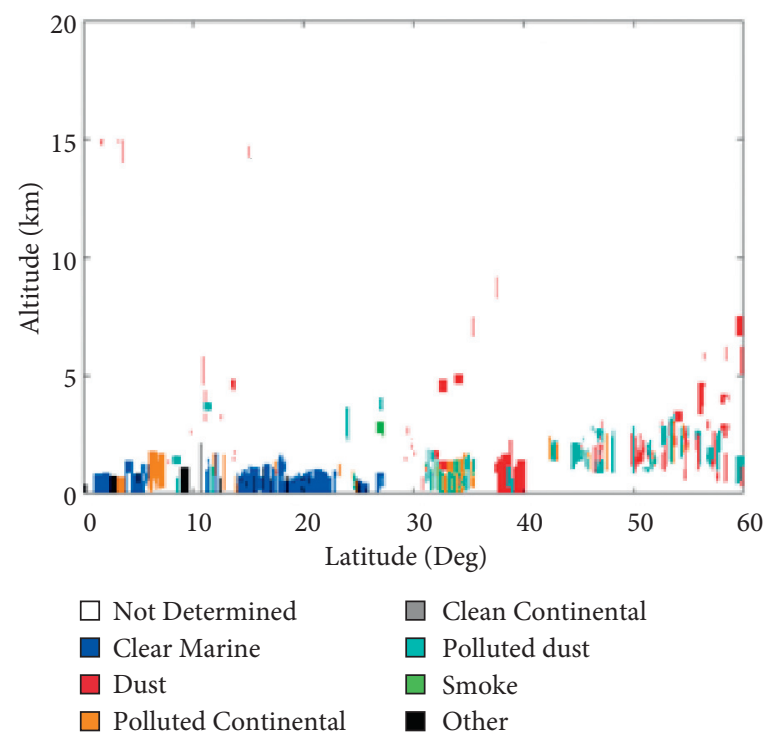

(c)

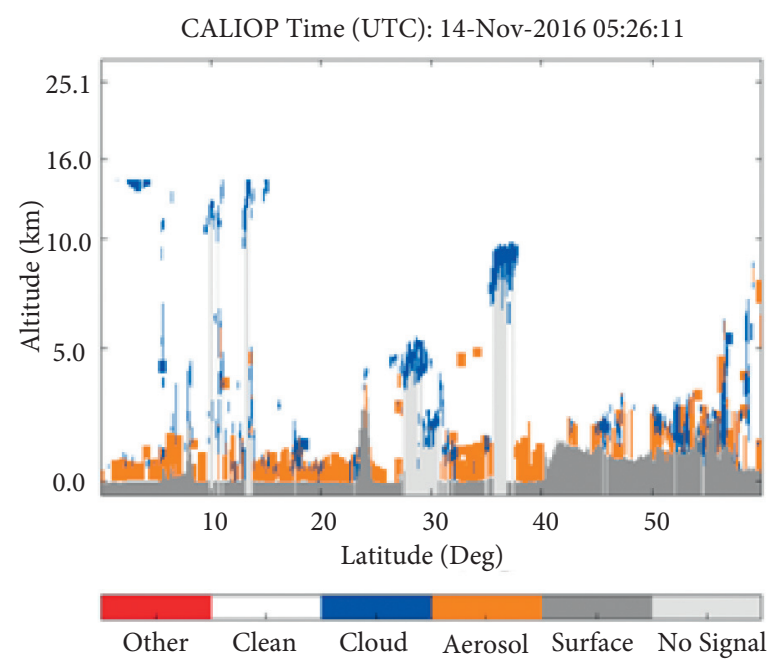

(b)

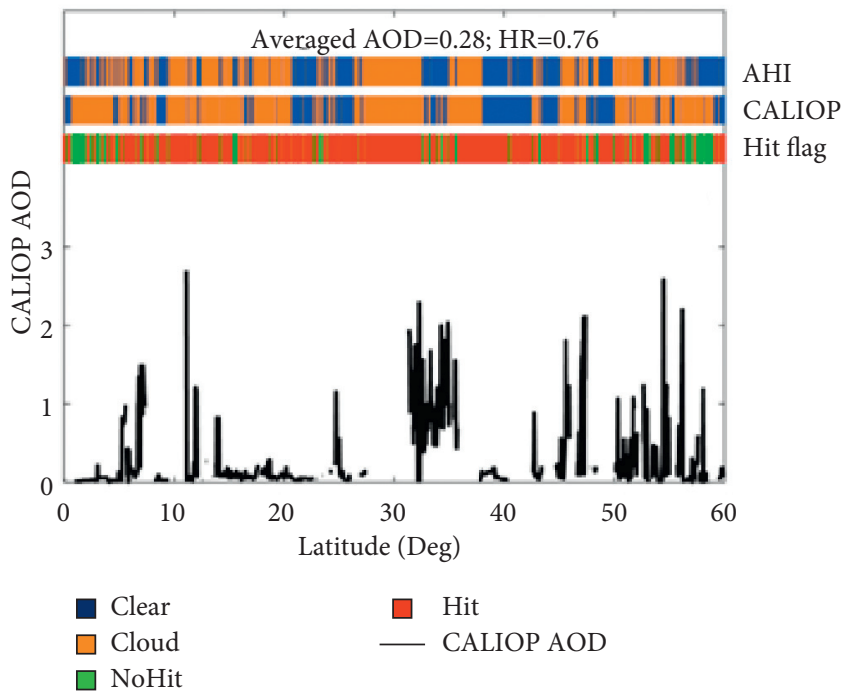

(d)

FIgURE 4: Comparison at 05:30 UTC, 14 December 2016. (a) AHI cloud-mask and the consistency line between AHI and CALIOP, with red for consistency and green for inconsistency; the black pentagrams refer to the in situ PM2.5 measurements. (b) VFM retrieved by CALIOP. (c) Aerosol types detected by CALIOP. (d) Cloud-mask of AHI and CALIOP AOD along the CALIPSO trajectory.

with heavy pollution levels from $32^{\circ} \mathrm{N}$ to $33^{\circ} \mathrm{N}$ as cloudy. On the contrary, CALIOP identified the corresponding pixels as clear (Figure 4(d)). Reasonably, the extremely high aerosol loading is a possible reason for the weak AHI sensitivity on broken clouds and reduction in the cloud-mask agreements (hit rate of 67\%) between AHI and CALIOP.

3.2. Long-Term Analysis. A preliminary conclusion based on these three cases can be derived, namely, increasing aerosol loading negatively influences the capability of AHI cloud detection. This conclusion should be further confirmed by a long-term statistical analysis. The relationship between surface pollution levels (PM2.5 concentrations) and HR (UR) of AHI cloud-mask in comparison with CALIOP for each PM2.5 bin is plotted in Figure 5. Overall, the average
HR and UR of clear (cloud) between the two sensors during the period are $79 \%(63 \%)$ and $5 \%(20 \%)$, respectively. A legible negative relationship between polluted loading and cloud (clear) HR is shown in the figure. On average, surface $\mathrm{PM}_{2.5}$ concentrations lower than $40 \mu \mathrm{g} / \mathrm{m}^{3}$ correspond to cloud (clear) HRs greater than $75 \%(88 \%)$, and $\mathrm{PM}_{2.5}$ loadings greater than $120 \mu \mathrm{g} / \mathrm{m}^{3}$ correspond to the cloud (clear) HRs lower than $30 \%(68 \%)$. On the contrary, the low URs with $15 \%$ of cloud and $3 \%$ of clear exist in low $\mathrm{PM}_{2.5}$ levels (lower than $40 \mu \mathrm{g} / \mathrm{m}^{3}$ ), while the high URs with $47 \%$ of cloud and $15 \%$ of clear exist in high $\mathrm{PM}_{2.5}$ levels (higher than $130 \mu \mathrm{g} / \mathrm{m}^{3}$ ). HRs (URs) of cloud and clean pixel demonstrate that the current algorithm has a higher ability on identifying clear pixels than cloud pixels. Therefore, the scenario indicates that the performance of AHI cloud-mask (clearmask) gradually decreases with the increasing surface 


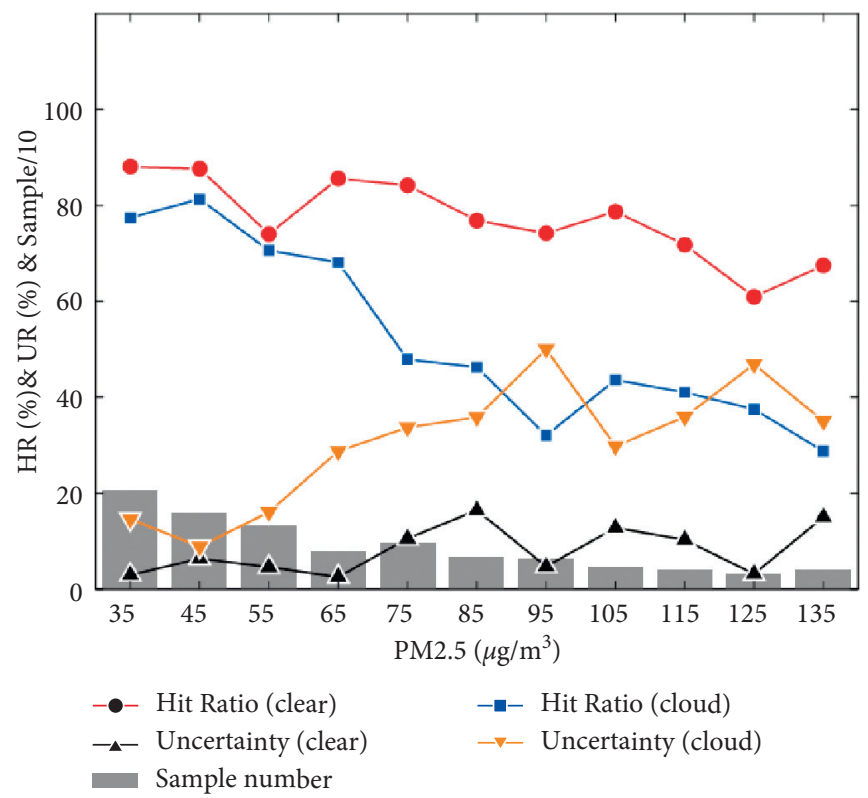

Figure 5: Hit ratio of cloud (clear) pixels from AHI and CALIOP and uncertainty ratio of cloud (clear) pixels for each PM2.5 bin from January 1, 2016, to December 31, 2019.

polluted loadings. The evidently positive relationship between URs and surface PM2.5 loadings indicates that the high pollution levels have a negative influence on AHI cloud identification over the study region.

\section{Conclusions}

The impact of pollution loadings on the performance of Himawari-8/AHI cloud-mask was explored by corresponding CALIOP cloud product with three typical cases and long-term analyses from January 1, 2016, to December 31,2019 . Three typical cases with different pollution loadings were selected to show the discrepancy of cloud-mask between AHI and CALIOP in detail. Then, the influence of pollution levels on the consistency (hit rate) of cloud-mask between AHI and CALIOP was analyzed based on a longterm statistical analysis. Three typical case analyses demonstrate that the disagreement of cloud-mask from AHI and CALIOP usually occurs in a track with high aerosol loading. Overall, the average HR and UR of clear (cloud) between the two sensors during the period are $79 \%$ (63\%) and 5\% (20\%). A legible negative relationship between polluted loading and cloud (clear) HR is demonstrated by the long-term analysis. On average, surface PM2.5 concentrations lower than $40 \mu \mathrm{g} /$ $\mathrm{m}^{3}$ correspond to cloud (clear) HRs greater than $75 \%(88 \%)$, and $\mathrm{PM}_{2.5}$ loadings greater than $120 \mu \mathrm{g} / \mathrm{m}^{3}$ correspond to the cloud (clear) HRs lower than $30 \%(68 \%)$. On the contrary, the low URs with $15 \%$ of cloud and $3 \%$ of clear exist in low $\mathrm{PM}_{2.5}$ levels (lower than $40 \mu \mathrm{g} / \mathrm{m}^{3}$ ), while the high URs with $47 \%$ of cloud and $15 \%$ of clear exist in high PM2.5 levels (higher than $130 \mu \mathrm{g} / \mathrm{m}^{3}$ ). The cloud-mask disagreements between AHI and CALIOP may be attributed to the AHI's poor ability to detect broken-low clouds.

This study has demonstrated that aerosol loading potentially affects the ability of AHI cloud detection. This finding suggests cautious use of the cloud-mask products from Himawari-8/AHI, especially in a region with high pollution loadings. Some thresholds applied in cloud detection algorithm of Himawari-8/AHI should be updated or revised.

\section{Data Availability}

Himawari-8 level 1 data can be accessed from http://www. eorc.jaxa.jp/ptree. CALIPSO cloud and aerosol products can be accessed from https://search.earthdata.nasa.gov/search. Surface polluted levels can be accessed from https://air. cnemc.cn:18007/.

\section{Conflicts of Interest}

The authors declare that they have no conflicts of interest.

\section{Acknowledgments}

We are grateful to the China National Environmental Monitoring Center (CNEMC), the National Aeronautics and Space Administration, and the Japan Aerospace Exploration Agency for providing the datasets used here. This study was supported by the National Natural Science Foundation of China (41901295), Basic Science Center Project of National Natural Science Foundation of China (72088101), Natural Science Foundation of Hunan Province, China (2020JJ5708), and Key Program of the National Natural Science Foundation of China (41930108).

\section{References}

[1] H. Letu, K. Yang, T. Y. Nakajima et al., "High-resolution retrieval of cloud microphysical properties and surface solar radiation using Himawari-8/AHI next-generation 
geostationary satellite," Remote Sensing of Environment, vol. 239, Article ID 111583, 2020.

[2] F. Mao, M. Duan, Q. Min, W. Gong, Z. Pan, and G. Liu, "Investigating the impact of haze on MODIS cloud detection," Journal of Geophysical Research: Atmospheres, vol. 120, 2015.

[3] B. Qiu, W. Li, M. Zhong, Z. Tang, and C. Chen, "Spatiotemporal analysis of vegetation variability and its relationship with climate change in China," Geo-Spatial Information Science, vol. 17, no. 3, pp. 170-180, 2014.

[4] Q. Min, B. Yin, S. Li et al., "A high-resolution oxygen A-band spectrometer (HABS) and its radiation closure," Atmospheric Measurement Techniques Discussions, vol. 7, pp. 1027-1057, 2014.

[5] Y. Zeng, W. Huang, F. Zhan, H. Zhang, and H. Liu, "Study on the urban heat island effects and its relationship with surface biophysical characteristics using MODIS imageries," GeoSpatial Information Science, vol. 13, no. 1, pp. 1-7, 2010.

[6] S. Ackerman, K. Strabala, P. Menzel, R. Frey, C. Moeller, and L. Gumley, "Discriminating clear-sky from cloud with MODIS algorithm theoretical basis document (MOD35)," Citeseer, 2010.

[7] K. Yumimoto, T. M. Nagao, M. Kikuchi et al., "Aerosol data assimilation using data from Himawari-8, a next-generation geostationary meteorological satellite," Geophysical Research Letters, vol. 43, no. 11, pp. 5886-5894, 2016.

[8] L. Wang, K. Cai, Y. Si, C. Yu, H. Zheng, and S. Li, "Evaluation of Himawari-8 Version 2.0 Aerosol Products against AERONET Ground-Based Measurements over Central and Northern China," Atmospheric Environment, vol. 224, 2020.

[9] K. Bessho, K. Date, M. Hayashi et al., "An Introduction to Himawari-8/9- Japan's New-Generation Geostationary Meteorological Satellites," Journal of the Meteorological Society of Japan. Ser. II, vol. 94, pp. 151-183, 2016.

[10] H. Letu, T. Y. Nakajima, T. Wang et al., "A new benchmark for surface radiation products over the East Asia-Pacific region retrieved from the Himawari-8/AHI next-generation geostationary satellite," Bulletin of the American Meteorological Society, pp. 1-40, 2021.

[11] X. Yang, C. Zhao, N. Luo, W. Zhao, W. Shi, and Y. Xing, "Evaluation and Comparison of Himawari-8 L2 V1.0, V2.1 and MODIS C6.1 Aerosol Products over Asia and the Oceania Regions," Atmospheric Environment, vol. 220, 2020.

[12] W. Wang, F. Mao, Z. Pan et al., "Evaluating aerosol optical depth from Himawari-8 with sun photometer network," Journal of Geophysical Research: Atmospheres, vol. 124, no. 10, pp. 5516-5538, 2019.

[13] H. Shang, L. Chen, H. Letu, M. Zhao, S. Li, and S. Bao, "Development of a daytime cloud and haze detection algorithm for Himawari-8 satellite measurements over central and eastern China," Journal of Geophysical Research: Atmospheres, vol. 122, no. 6, pp. 3528-3543, 2017.

[14] R. E. Holz, S. Platnick, K. Meyer et al., "Resolving ice cloud optical thickness biases between CALIOP and MODIS using infrared retrievals," Atmospheric Chemistry and Physics, vol. 16, no. 8, pp. 5075-5090, 2016.

[15] D. Zhang, D. Liu, T. Luo, Z. Wang, and Y. Yin, "Aerosol impacts on cloud thermodynamic phase change over East Asia observed with CALIPSO and CloudSat measurements," Journal of Geophysical Research: Atmospheres, vol. 120, no. 4, pp. 1490-1501, 2015.

[16] M.-H. Kim, A. H. Omar, J. L. Tackett et al., "The CALIPSO version 4 automated aerosol classification and lidar ratio selection algorithm," Atmospheric Measurement Techniques, vol. 11, no. 11, pp. 6107-6135, 2018.
[17] Z. Liu, R. Kuehn, M. Vaughan et al., "The CALIPSO cloud and aerosol discrimination: version 3 algorithm and test results," in Proceedings of the 25th International Laser Radar Conference, pp. 155-158, St. Petersburg, Russia, July 2010.

[18] T. Shi, G. Han, X. Ma et al., "Quantifying CO2 uptakes over oceans using LIDAR: a tentative experiment in Bohai bay," Geophysical Research Letters, vol. 48, Article ID e2020GL091160, 2021.

[19] T. J. Thorsen, Q. Fu, R. K. Newsom, D. D. Turner, and J. M. Comstock, "Automated retrieval of cloud and aerosol properties from the ARM Raman lidar. Part I: feature detection," Journal of Atmospheric and Oceanic Technology, vol. 32, no. 11, pp. 1977-1998, 2015.

[20] J. Guo, B. Liu, W. Gong et al., "Technical note: first comparison of wind observations from ESA's satellite mission Aeolus and ground-based radar wind profiler network of China," Atmospheric Chemistry and Physics, vol. 21, no. 4, pp. 2945-2958, 2021.

[21] J. Yang, S. Yang, Y. Zhang, S. Shi, and L. Du, "Improving characteristic band selection in leaf biochemical property estimation considering interrelations among biochemical parameters based on the PROSPECT-D model," Optics Express, vol. 29, no. 1, pp. 400-414, 2021.

[22] W. Wang, J. He, Z. Miao, and L. Du, "Space-Time Linear Mixed-Effects (STLME) model for mapping hourly fine particulate loadings in the Beijing-Tianjin-Hebei region, China," Journal of Cleaner Production, vol. 292, Article ID 125993, 2021.

[23] M. Kikuchi, H. Murakami, K. Suzuki, T. M. Nagao, and A. Higurashi, "Improved hourly estimates of aerosol optical thickness using spatiotemporal variability derived from Himawari-8 geostationary satellite," IEEE Transactions on Geoscience and Remote Sensing, vol. 56, no. 6, pp. 3442-3455, 2018.

[24] T. Imai and R. Yoshida, "Algorithm Theoretical Basis for Himawari-8 Cloud Mask Product," Meterological Satellite Technical Note, vol. 61, 2015.

[25] Z. Liu, M. Vaughan, D. Winker et al., "The CALIPSO lidar cloud and aerosol discrimination: version 2 algorithm and initial assessment of performance," Journal of Atmospheric and Oceanic Technology, vol. 26, no. 7, pp. 1198-1213, 2009.

[26] Y. Ma, W. Gong, and F. Mao, "Transfer learning used to analyze the dynamic evolution of the dust aerosol," Journal of Quantitative Spectroscopy and Radiative Transfer, vol. 153, pp. 119-130, 2015.

[27] L. Dong, Z. Wang, Z. Liu, D. Winker, and C. Trepte, "A height resolved global view of dust aerosols from the first year CALIPSO lidar measurements," Journal of Geophysical Research Atmospheres, vol. 113, Article ID D16214, 2008.

[28] D. L. Wu, S. A. Ackerman, R. Davies et al., "Vertical distributions and relationships of cloud occurrence frequency as observed by MISR, AIRS, MODIS, OMI, CALIPSO, and CloudSat," Geophysical Research Letters, vol. 36, 2009.

[29] B. H. Kahn, M. T. Chahine, G. L. Stephens et al., "Cloud type comparisons of AIRS, CloudSat, and CALIPSO cloud height and amount," Atmospheric Chemistry and Physics, vol. 8, no. 5, pp. 1231-1248, 2008.

[30] W. Wang, F. Mao, B. Zou et al., "Two-stage model for estimating the spatiotemporal distribution of hourly PM1.0 concentrations over central and east China," The Science of the Total Environment, vol. 675, pp. 658-666, 2019. 